\title{
Sostenibilidad sociocultural del turismo: propuestas para el cantón Playas. Provincia del Guayas, Ecuador
}

\section{José Lázaro Quintero Santos}

PhD. Profesor Investigador Proyecto Prometeo, SENESCYT. Universidad Tecnológica Equinoccial, Quito, Ecuador; jlqacuario@yahoo.es

Recibido: 11 de febrero, 2015 - Aceptado: 11 de setiembre, 2015 - Corregido: 19 de octubre, 2015

\section{RESUMEN}

Este artículo forma parte de la investigación "Propuesta de un Modelo de Desarrollo Turístico Sostenible para el cantón Playas, provincia del Guayas, Ecuador". En este caso solo se hace referencia a la propuesta de un modelo de sostenibilidad sociocultural de los impactos del turismo. La investigación se realiza en el cantón Playas debido a la importancia estratégica que tiene el desarrollo del turismo para este territorio gracias a su efecto multiplicador en el resto de las actividades económicas. La metodología de la investigación ha incluido un estudio cuantitativo y cualitativo del territorio, así como, entrevistas y encuestas a los actores locales. Para lograr el objetivo de esta investigación se ha realizado un análisis social y cultural considerando los recursos patrimoniales y socioculturales de la zona. El estudio comprende programas y proyectos que permiten formular una propuesta de turismo sostenible que sea inclusiva y respetuosa con las comunidades y sus culturas.

Palabras claves: Modelo de desarrollo, turismo sostenible, desarrollo del turismo, estrategias de desarrollo, impactos socioculturales del turismo.

\author{
ABSTRACT \\ Tourism Socio-cultural sustainability: \\ Proposal for cantón Playas. Provincia del Guayas, Ecuador.
}

This article is part of the research proposal: Sustainable Tourism Development Model for the canton Playas, Provincia del Guayas, Ecuador. The research proposes a model of sociocultural sustainability for the impact of tourism in the region. The current research takes the canton Playas due to the strategic importance and multiplying effect that tourism development has for this locality and its economic activities. The research methodology includes a quantitative and qualitative study of the territory, as well as interviews and surveys with local stakeholders. To

\section{Formato de citación según APA}

Quintero Santos, J.L. (2016). Sostenibilidad sociocultural del turismo: propuestas para el cantón Playas. Provincia del Guayas, Ecuador. Revista Espiga, Vol XV, (31), 31-43. 
achieve the objectives of this research project, a social and cultural analysis has been carried out considering the economic and socio-cultural resources of the territory. The study includes programs and projects that allow formulating a proposal for sustainable tourism.

Key words: tourism model, sustainable tourism, tourism development, development strategies, sociocultural impacts of tourism.

\section{Introducción}

Tradicionalmente, el turismo no ha sido una de las actividades económicas prioritarias el Ecuador. No obstante, en los últimos años el gobierno ecuatoriano ha realizado múltiples esfuerzos para posicionar internacionalmente a Ecuador como un destino atractivo por su riqueza en diversidad biológica, histórica y cultural a través de sus cuatro mundos: costa, Andes, Amazonía y Galápagos. En la actualidad se hacen grandes esfuerzos para desarrollar el turismo por medio de diversas estrategias y programas. Uno de esos programas es el Proyecto Prometeo, el cual permite contratar a expertos de alto nivel de diversos países, a través de un programa de becas, para participar en proyectos de investigación y formación del talento humano.

Este estudio forma parte de un proyecto de investigación para la formulación de estrategias de desarrollo del turismo en la provincia del Guayas. En este caso, se ha tomado como referencia el cantón Playas con el objetivo de proponer un Modelo de Sostenibilidad Sociocultural de Desarrollo del Turismo que permita diversificar la oferta.

El cantón Playas se encuentra en el suroeste de la provincia del Guayas, en la República del Ecuador, y su cabecera cantonal es General José de Villamil. El cantón está ubicado a 96 kilómetros de la ciudad de Guayaquil y tiene una población aproximada de 42000 habitantes. Se

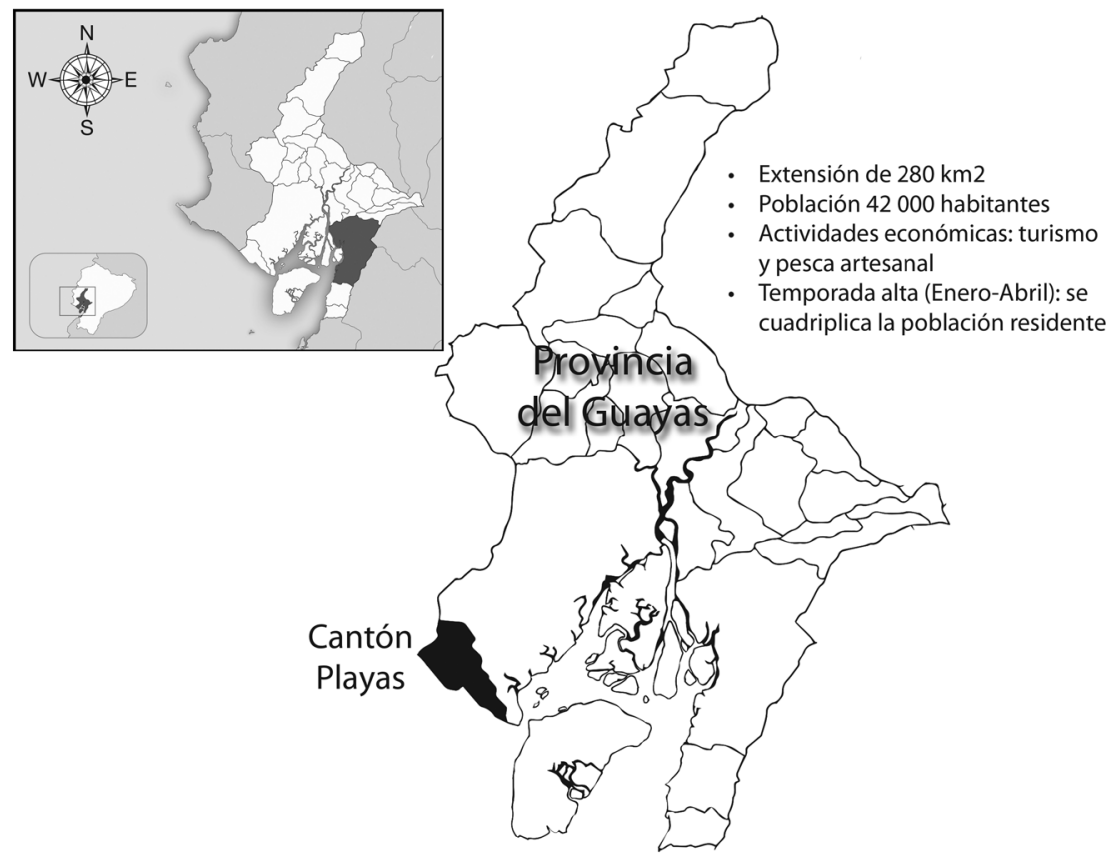

Figura 1. Cantón Playas. Fuente: Elaboración a partir del plan estratégico de desarrollo del turismo en la provincia del Guayas, Ecuador. 
encuentra limitada al norte y al este con los cantones Guayaquil y Santa Elena; y al sur y oeste con el Océano Pacífico (GPG, 2012)

La economía del cantón es conformada por actividades del sector primario, sector secundario y sector terciario. El sector primario comprende todas aquellas actividades relacionadas directamente con la naturaleza tales como: la agricultura, silvicultura, caza, pesca y ganadería. En el cantón Playas estas comprenden la pesca, agricultura, ganadería y cultivo de camarón (acuacultura).

El sector secundario es aquel que procesa y transforma la materia prima en productos para el consumo o en equipos y maquinarias. En el cantón Playas hay muy pocas industrias. En la investigación se identificaron una peladora de camarón y una empacadora exportadora de mariscos, denominada NATLUK.

El sector terciario está constituido por actividades generadoras de servicios como: electricidad, gas y agua; comercio, hoteles, bares, restaurantes, transporte, comunicaciones, finanzas, bancos e inmobiliarias, alquiler de vivienda, servicios prestados a empresas y a hogares, entre otras. En relación con estas actividades económicas en el cantón Playas destacan: alojamiento, restauración y comercio (artesanías)

Debido a su ubicación geográfica, el producto turístico que atrae a los visitantes al cantón es el disfrute de sus extensas playas. Por otra parte, el turismo comunitario se desarrolla básicamente en la comuna de Puerto Engabao. Este es un territorio dentro del cantón, que tiene un promedio de 300 habitantes repartidos en 70 familias (GADMCP, 2012) La actividad económica fundamental de Puerto Engabao es la pesca artesanal; por lo tanto, se caracteriza por ser un pueblo pesquero. Uno de sus recursos naturales más importantes son sus playas, las cuales se caracterizan por el fuerte oleaje de sus aguas durante todo el año. Este factor atrae el turismo nacional e internacional, específicamente a quienes tienen un interés deportivo, siendo la práctica de surf la más común.
Actualmente, muchas de las casas de los habitantes de Puerto Engabao se ofrecen como hospedaje comunitario con precios muy económicos ( 10 - 25 dólares la noche como promedio, según encuestas realizadas). En este sentido, los turistas tienen la posibilidad de convivir dentro de un hogar comunitario con facilidades y servicios básicos de calidad media baja.

\section{Revisión teórica}

El desarrollo de las actividades turísticas en general y de los diferentes productos turísticos en particular está fuertemente vinculado a los efectos económicos que ese desarrollo puede provocar en los destinos turísticos. Tal es así, porque como han señalado muchos especialistas (Pedreño Muñoz, 1996:22) la demanda que generan los turistas provoca impactos en el resto de las actividades económicas.

Esos impactos, denominados por la comunidad científica como "efecto multiplicador del turismo" están íntimamente relacionados con el potencial que tienen los territorios. En este sentido, el turismo es capaz de convertirse en una actividad (económica, sociocultural y medioambiental) que estimula y contribuye a un mejoramiento de las condiciones de vida de la población a través del desarrollo de aquellas actividades que están vinculadas al turismo (Quintero Santos, 2014b:33)

Como se afirma en un estudio reciente (CET y OMT, 2013) al hablar de "productos turísticos" se refiere a múltiples componentes tan diversos como los parajes naturales, la historia y el patrimonio cultural, el entorno arquitectónico y la propia población del destino. El estudio hace referencia a que un paisaje pintoresco, un parque temático y un concierto de música clásica son ejemplos de productos turísticos, al igual que el esquí acuático, el snowboard, la escalada, los cursos de preparación de platos o especialidades locales, o la práctica de la artesanía tradicional del destino. Además, cada producto turístico tiene un impacto en el lugar donde se desarrollan las actividades turísticas. 
Desde la perspectiva sociocultural la magnitud de los impactos dependerá, en gran medida, de las diferencias socioculturales entre turistas y residentes. Estos pueden afectar a multitud de variables, entre ellas: formas de vida, sistemas de valores, comportamiento individual, niveles de seguridad, conducta moral y política y cultura tradicional.

De acuerdo con estudios realizados en relación con los impactos socioculturales y medio ambientales del turismo (Berger, 2000:16; César Dachary y Arnaiz Burne, 2002:72; Crosby y Moreda, 1999:123; Díaz Álvarez, 1996:275; Picornell, 1993:83) se señala que las relaciones turistas - residentes pasan por las etapas de euforia, apatía, irritación, antagonismo y una fase final de claro declive difícil de remontar. A su vez, estos estudios demuestran que las presiones del turismo sobre el medio ambiente natural pueden ocasionar la aparición del estrés ambiental, cuando los niveles de tolerancia son superados por la acción destructiva y la sobreexplotación del entorno natural.

Precisamente esos impactos negativos obligan al desarrollo de estrategias sostenibles (Figura II) con sus respetivos proyectos y programas. En este sentido, el logro de un turismo sostenible es un proceso continuo y requiere un seguimiento constante de los impactos, para introducir modelos y medidas preventivas o correctivas que resulten necesarias.

Por lo tanto, la implicación directa de los gobernantes más cercanos a los ciudadanos (municipios y otras administraciones locales) y la participación activa de los agentes económicos y la sociedad civil es determinante para promover un binomio turista-residente que los haga más conscientes de los problemas de la sostenibilidad y fomente en ellos prácticas turísticas sostenibles.

Para Rivas (2010: 382), desde el punto de vista del lugar y la comunidad local, es imprescindible considerar el respeto del turismo hacia la identidad y los valores socioculturales, mientras que la satisfacción de la demanda turística constituye un aspecto clave de la eficiencia económica del turismo. El desarrollo turístico debe ser sostenible a largo plazo, viable económicamente y equitativo, desde una perspectiva ética y social para las comunidades locales.

En la actualidad muchos profesionales del turismo están preocupados por el impacto que genera el turismo en las regiones receptoras. Esto ha originado diferentes enfoques que abogan por que la práctica del turismo sea respetuosa, ética,

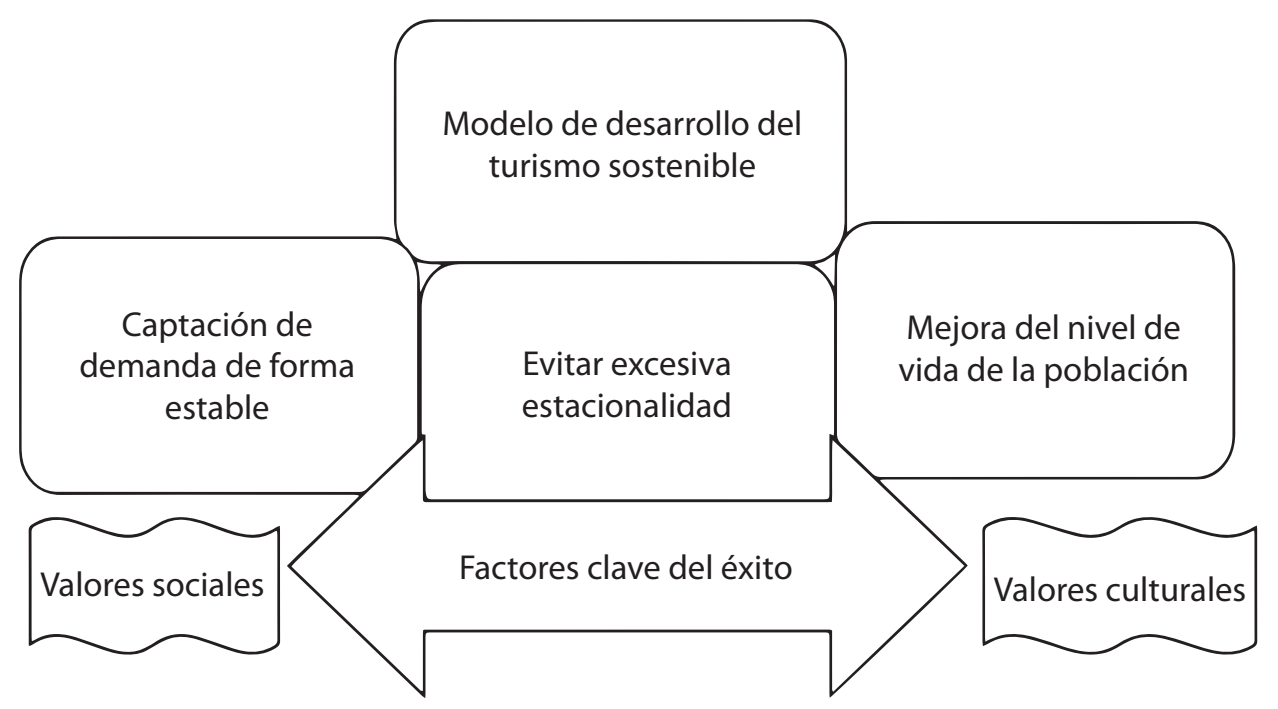

Figura 2. Estrategias de desarrollo del turismo. Fuente: Elaboración propia. 
de bajo impacto ambiental, que evite la desculturización de los destinos turísticos, que proteja la fragilidad de zonas sensibles que se masifican a favor de intereses mercantilistas, que se tenga en cuenta la integración de la población local en la conformación de la oferta turística y que el turismo se desarrolle siguiendo los principios de sostenibilidad (Quintero Santos, 2014:28).

\section{Metodología}

La metodología de la investigación se ha basado en un estudio cuantitativo y cualitativo del cantón Playas, el cual incluyó un diagnóstico para identificar las condicionantes que el desarrollo de actividades turísticas y recreativas impone a los procesos de planificación del territorio. Se estudiaron los instrumentos y las estrategias de planificación a implementar y se analizaron las características y resultados de los procesos económicos, sociales y medioambientales de los periodos anteriores, poniendo de manifiesto sus principales logros y limitaciones. La investigación se dividió en las siguientes etapas. La primera etapa constituyó el trabajo documental. La segunda etapa, el trabajo de campo, el cual incluyó entrevistas, encuestas, reuniones y talleres dirigidos al sector público, sector privado y sociedad civil. La tercera etapa consistió en el trabajo analítico. Para llevar a cabo esta sección se emplearon las técnicas siguientes: lluvia de ideas, diagramas tipo causa efecto, matrices FODA, el Balanced Scorecard (cuadro de mando integral) y matrices de análisis estratégico. Como última etapa, se elaboró una propuesta.

El material bibliográfico básico para el desarrollo de la investigación, entre otros, han sido publicaciones relacionadas con los impactos del turismo, "Plan Nacional del Buen Vivir 2013-2017 del Ecuador", "Plan Estratégico de Desarrollo de Turismo Sostenible para Ecuador (PLANDETUR 2020)", documento "Consenso de Quito sobre Turismo Consciente en las Américas (13 de septiembre de 2012)", "Plan Maestro de Desarrollo Turístico de la Provincia del Guayas", documento "Prioridades para el Desarrollo Integral y Articulación de Redes Territoriales del
Cantón Playas" y los "Planes de Desarrollo y Ordenamiento Territorial del Cantón Playas".

La interrogante fundamental que ha servido de base para el desarrollo de la investigación es la siguiente: ¿Cuáles son las condicionantes que permiten que el turismo se convierta en el motor del desarrollo del cantón Playas a partir de sus impactos socioculturales? Para dar respuesta a la interrogante el estudio se ha realizado interrelacionando la variable turismo con los impactos socioculturales, lo cual permitió formular la hipótesis de investigación siguiente:

"Si el cantón Playas tiene recursos socioculturales que constituyan la base de sus capacidades actuales y/o potenciales para el desarrollo del turismo, entonces, es viable diseñar un modelo de sostenibilidad sociocultural a partir de las interrelaciones que se establecen entre los turistas y la población local”.

\section{Justificación:}

La actividad turística constituye un marco donde entran en contacto personas de culturas y entornos socioeconómicos muy diferentes, ya que implica el desplazamiento de turistas a una región distinta del lugar de su residencia habitual. Los impactos socioculturales en un destino son el resultado de dichas relaciones sociales mantenidas durante la permanencia de los visitantes en los destinos turísticos. La relación del turista con la población local genera consumos por parte del turista que implican aceptación, rechazo, indiferencia y/o integración al compartir los mismos espacios e intercambiar bienes, servicios e informaciones.

\section{Propuesta del Modelo de Sostenibilidad Sociocultural de Desarrollo del Turismo}

Un Modelo de Sostenibilidad Sociocultural de Desarrollo del Turismo (figura III) debe estar acorde con los valores y la cultura del territorio, fortaleciendo así la identidad del mismo. Un modelo de esta índole implica de manera imprescindible la solidaridad, el respeto mutuo y la participación de la sociedad civil y de todos 


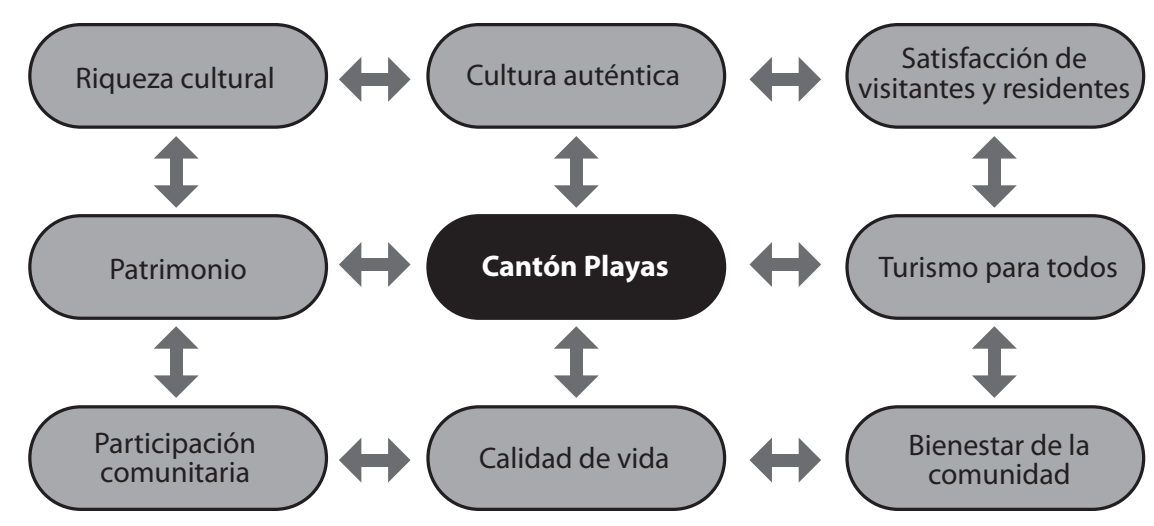

Figura 3. Modelo de Sostenibilidad Sociocultural de Desarrollo del Turismo. Fuente: Elaboración propia.

los agentes públicos y privados implicados en el proceso.

El modelo vincula cuatro componentes que están interrelacionados entre sí:

\section{Satisfacción de visitantes y residentes}

Procurar una práctica turística segura, excelente y total a los visitantes con igualdad de oportunidades (turismo para todos). Además, el turismo tiene como obligación garantizar la satisfacción del residente frente a la actividad turística, asegurando así una experiencia enriquecedora para la localidad anfitriona.

\section{Bienestar de la comunidad}

Fortalecer y asegurar la calidad de vida de las comunidades locales, incluyendo los accesos a recursos y servicios básicos, evitando así alguna forma de explotación social. Mejorar la calidad de vida mediante el desarrollo de infraestructura turística y el fortalecimiento del patrimonio cultural.

\section{Riqueza cultural}

Restaurar y respetar el patrimonio, la cultura y las tradiciones de las comunidades que conforman el territorio. El componente mencionado se enfatiza mediante un proyecto de recuperación, revalorización y desarrollo del patrimonio cultural, histórico e intangible de la localidad.

\section{Participación comunitaria}

Desarrollar un conjunto de estrategias, programas y proyectos que permitan de manera coordinada el logro de propósitos comunes de bienestar, convivencia y calidad de vida para todos los grupos sociales que se encuentran en el territorio. La participación comunitaria debe ser entendida como un proceso de cooperación y negociación entre actores. En este sentido se deben unir fuerzas y recursos que permitan formas de colaboración para estimular las iniciativas locales y concretarlas.

La propuesta del modelo de sostenibilidad social y cultural del desarrollo del turismo es necesaria con el fin de diversificar la oferta del cantón Playas. Con este modelo se busca aumentar la competitividad de la localidad, sustentada en sus atractivos culturales y patrimoniales. El modelo presenta una serie de estrategias, políticas, programas y proyectos para su implementación que deben ser debatidas por todos los actores locales.

\section{Estrategias de desarrollo del Modelo de Sostenibilidad Sociocultural del Turismo para el cantón Playas}

\section{Objetivos}

- Convertir al turismo sostenible en una estrategia que potencie el desarrollo integral. 
- Posicionar al cantón Playas como un destino turístico sostenible que ayude a lograr los Objetivos de Desarrollo del Milenio con una efectiva gestión socio-cultural ${ }^{1}$.

- Producir una oferta turística sostenible y competitiva que potencie los recursos culturales del territorio.

- Captar una demanda turística nacional e internacional consciente de la sostenibilidad y con mayor propensión al gasto.

Políticas de desarrollo del turismo para el cantón Playas

- Turismo sostenible como modelo de desarrollo sociocultural para contribuir al logro de los Objetivos de Desarrollo del Milenio (ODM).

- Mejorar la calidad de vida de los habitantes de las diferentes comunidades del cantón.
- Valorizar y conservar el patrimonio cultural del territorio.

\section{Estrategias}

Las estrategias que deben permitir el logro de los objetivos son las siguientes:

1. Fortalecer la actividad turística sostenible en el cantón Playas en el ámbito social y cultural.

2. Utilizar a la actividad turística como vía para el cumplimiento de los Objetivos de Desarrollo del Milenio, permitiendo principalmente la reducción de la pobreza y la conservación del patrimonio cultural.

3. Equipar y dotar al cantón Playas de los elementos necesarios que permitan la creación de un producto turístico competitivo y diferenciado.

Propuesta de programas y proyectos:

\begin{tabular}{ll}
\multicolumn{1}{c}{ Programa 1 } & \multicolumn{1}{c}{ Proyectos } \\
$\begin{array}{ll}\text { Recuperación, revalorización y desarrollo del } \\
\text { patrimonio cultural, histórico e intangible con } \\
\text { perspectiva de sostenibilidad. }\end{array}$ & $\begin{array}{l}\text { Restauración y recuperación del edificio de la ex Academia } \\
\text { Militar Juan Gómez Rendón. } \\
\text { Revalorización de las balsas de tres boyas. }\end{array}$ \\
& $\begin{array}{l}\text { Restauración de la gráfica popular de las embarcaciones de los } \\
\text { pescadores de Puerto Engabao. }\end{array}$ \\
& $\begin{array}{l}\text { Creación de una ruta turística que ponga en valor la identidad } \\
\text { y la cultura del Cantón Playas. }\end{array}$ \\
\hline
\end{tabular}

Fuente: Elaboración propia.

1. Los Objetivos de Desarrollo del Milenio, también conocidos como Objetivos del Milenio (ODM) son ocho propósitos de desarrollo humano fijados en el año 2000 por los 189 países miembros de las Naciones Unidas. Estos objetivos deben ser cumplidos para el año 2015. Los objetivos tratan problemas de la vida cotidiana que se consideran graves y/o radicales y son: 1. Erradicar la pobreza extrema y el hambre, 2. Lograr la enseñanza primaria universal, 3. Promover la igualdad entre los géneros y la autonomía de la mujer, 4. Reducir la mortalidad infantil, 5. Mejorar la salud materna, 6. Combatir el VIH/ SIDA, el paludismo y otras enfermedades infecto-contagiosas, 7. Garantizar la sostenibilidad del medio ambiente. En: http://www.un.org/es/millenniumgoals/ 
Los objetivos de este programa son contribuir al desarrollo local, diversificar la oferta turística y conservar, restaurar y proteger la cultura y el patrimonio cultural. Además, el programa tiene como meta de gestión captar una demanda turística sostenible durante todo el año que disfrute, respete, ayude a conservar y valore el patrimonio cultural.

\subsection{Proyecto "Restauración y recuperación del edificio de la ex Academia Militar Juan Gómez Rendón"}

El edifico de la ex Academia Militar es una joya arquitectónica que se encuentra en una situación de abandono y deterioro progresivo. Este edificio en ruinas tiene una historia y gran importancia como patrimonio del cantón Playas, por lo tanto, se debe restaurar para su utilización de la manera más conveniente. La recuperación de este patrimonio arquitectónico y cultural ayudaría a diversificar la oferta que tiene la localidad para el turista. Han existido propuestas que van desde recuperar el edificio como sede del gobierno municipal, hasta la creación de un hotel escuela y centro de convenciones.

\subsection{Proyecto \\ "Revalorización de las balsas de tres boyas"}

Las balsas de tres boyas son únicas en la región y desde hace muchos años son utilizadas para navegar y pescar. El objetivo del proyecto es posicionar las balsas en el mercado turístico de la provincia del Guayas y lograr que sean identificadas como patrimonio cultural del cantón Playas.

\section{Situación actual}

Las balsas de tres boyas del cantón Playas poseen valor histórico y cultural. Estas actualmente son utilizadas para la pesca artesanal y como atractivo turístico. Sus dueños las han diseñado con colores para que sean más llamativas; sin embargo, existe poca promoción y conocimiento de este recurso como patrimonio. Con la revalorización de las balsas se conseguirá diversificar las motivaciones de viajes para los turistas que visitan General Villamil (cabecera cantonal). El objetivo es que estas aporten un conocimiento de la cultura y la historia para quienes visiten el cantón Playas.

\subsection{Proyecto "Reestructuración de la gráfica popular de las embarcaciones de los pescadores de Puerto Engabao"}

Las embarcaciones de los pescadores de Puerto Engabao se pueden convertir en un recurso turístico cultural como sistema-producto articulado que se extienda más allá de las embarcaciones e incluya a la población local. El objetivo de este proyecto es contribuir a preservar el patrimonio cultural inmaterial (embarcaciones pesqueras) mediante la gráfica popular.

\section{Situación actual}

En Puerto Engabao existen embarcaciones pesqueras que se caracterizan por sus colores, tipografía, santoral pintado (las embarcaciones están pintadas con simbologías y alegorías a divinidades de la religión cristiana). Esto forma parte de la identidad cultural de este pueblo pesquero, en el cual se desarrolla el turismo comunitario. Las embarcaciones no han sido reconocidas ni como patrimonio ni como recurso turístico cultural. Por lo tanto, su reconocimiento contribuirá a que la identidad cultural local pueda convertirse en difusora de la gráfica popular, y aporte valor agregado a Puerto Engabao. De esta forma el turista podrá disfrutar de una experiencia diferente.

\subsection{Proyecto "Creación de una ruta turística que realce la identidad y cultura del Cantón Playas"}

Una ruta turística es un recorrido especialmente diseñado para los viajes de recreo o placer en transporte propio o turístico por los diferentes atractivos que ofrece un territorio. El objetivo de este proyecto es promover el turismo cultural en el cantón Playas a través de la creación de una ruta turística. 


\section{Situación actual}

A partir de la investigación realizada y estudios del Instituto Nacional de Patrimonio Cultural (INPC, 2010) gran parte del patrimonio cultural del cantón Playas no es reconocido por las autoridades locales y provinciales, ni conocido como tal por los habitantes del cantón ni por los visitantes. A su vez, esto lo confirma el hecho de que en entrevistas y encuestas realizadas a autoridades locales y provinciales, población residente y turistas más del $75 \%$ de los entrevistados y encuestados tenía poco o nulo conociendo acerca del patrimonio material e inmaterial que existe en la región. Esto se debe a que el cantón solo se concibe como un destino de sol y playas.

En este sentido, se propone la creación de la ruta "Los caminos del Patrimonio". Una oferta cultural e histórica que permita captar nuevos segmentos de la demanda e incidir en la reducción de la estacionalidad de la demanda. Los patrimonios a tomar en consideración son: el edificio de la ex Academia Militar Juan Gómez Rendón, la Escuela e Iglesia de la Cruz Roja, la casa de Jorge Macías, la Vivienda del Señor Eduardo Suárez, la Casa de los Herederos Hernández Álvarez y el sector donde se encuentran las balsas de tres boyas.

Propuesta de programas y proyectos:

\section{Programa 2}

Centro de espectáculos y 2.1. Creación de una expresiones culturales. concha acústica.

Fuente: Elaboración propia.

El objetivo de este programa es facilitar que las expresiones culturales del cantón Playas sean objeto de atracción para residentes y turistas. Esto permite reforzar la identidad y la autoestima social. Además, el programa tiene como meta de gestión diversificar la oferta turística del cantón y contribuir al desarrollo del turismo cultural en el territorio.

\subsection{Proyecto "Creación de la Concha Acústica".}

La concha acústica es una superficie curva tras el escenario que permite que el sonido se proyecte hacia adelante. Una concha acústica se considera un teatro al aire libre. El objetivo de este proyecto es promover actividades culturales para disfrute de residentes, visitantes y turistas. La construcción de la concha acústica podría estar ubicada en el parque conocido por los habitantes de la localidad, como "Parque Skate".

\section{Situación actual}

El "Parque Skate" es usado en su mayoría por niños y jóvenes que se divierten en sus instalaciones, a pesar de que estas no se encuentran en buen estado. Con este proyecto el parque puede convertirse en un área donde todos los habitantes, visitantes y turistas puedan disfrutar de actividades culturales, tales como: espectáculos de danza folklórica; presentaciones de grupos de teatros; presentaciones de artistas locales y nacionales, entre otras.

Programas y proyectos:

\begin{tabular}{cc}
\multicolumn{1}{c}{ Programa 3 } & \multicolumn{1}{c}{ Proyecto } \\
Infraestructura turística. & $\begin{array}{l}\text { 3.1. Creación de un mira- } \\
\text { dor en Puerto Engabao. }\end{array}$ \\
Fuente: Elaboración propia. &
\end{tabular}

El objetivo del programa es mejorar la infraestructura y servicios básicos que sirven de apoyo a la actividad turística. Además, el programa tiene como meta de gestión: diversificar la oferta turística del cantón Playas; contribuir a la calidad de vida de las comunidades y ayudar a aumentar la satisfacción del visitante.

\subsection{Proyecto "Creación de un mirador turístico en Puerto Engabao"}

Un mirador turístico es un elemento arquitectónico que se encuentra ubicado en lugares 
altos. Por ejemplo, la cima de cerros o acantilados a la orilla del mar. El objetivo de este proyecto es la creación de un mirador turístico en Puerto Engabao que contribuya al desarrollo de la oferta turística. El mirador debe construirse en el sector del faro de Puerto Engabao, por su altura y ubicación estratégica.

\section{Situación actual}

El sector del faro de Puerto Engabao se encuentra abandonado. Los pobladores y personas que visitan el lugar disfrutan de esta formación natural. Desde aquí se pueden observar las embarcaciones de los pescadores del lugar cuando salen y regresan de realizar la pesca artesanal. Con la construcción del mirador se pretende aumentar la llegada de visitantes y turistas al lugar. Hay que tener en cuenta que Puerto Engabao es un lugar que atrae visitantes y turistas por la práctica del surf.

Propuesta de programas y proyectos:

\begin{tabular}{ll}
\multicolumn{1}{c}{ Programa 4} & \multicolumn{1}{c}{ Proyecto } \\
Facilitación & 4.1. Centro de asistencia al turista. \\
turística. & $\begin{array}{l}\text { 4.2. Accesibilidad a las playas y sitios } \\
\text { patrimoniales para discapacitados. }\end{array}$ \\
& $\begin{array}{l}\text { 4.3. Señalización vial, urbana, rural y } \\
\text { de sitios de patrimonio cultural. }\end{array}$
\end{tabular}

Fuente: Elaboración propia.

El objetivo de este programa es proporcionar facilidades para la satisfacción de los visitantes y turistas que garantice mayor estadía, movilización y disfrute de los sitios visitados. Además, el programa tiene como meta de gestión implementar un sistema de asistencia técnica, información y seguridad turística en los lugares más concurridos del cantón Playas.

\subsection{Proyecto "Centro de asistencia al turista"}

Crear un centro de asistencia al turista dotado de infraestructuras (internet, teléfonos, servicios recepción de denuncias, reclamaciones y auxilio), y que a su vez, pueda funcionar como un observatorio de turismo que emita información actualizada sobre la demanda y la oferta turística.

\subsection{Proyecto "Acceso a las Playas y sitios patrimoniales para discapacitados"}

La accesibilidad para todos y la inclusión social son principios que tienen que estar presentes en todas las estrategias de desarrollo de turismo sostenible. Para el cantón Playas es un desafío crear condiciones para recibir a quienes presentan alguna discapacidad, y que muchas veces no hacen turismo por no tener un lugar accesible a sus necesidades. El objetivo es que personas discapacitadas puedan disfrutar de las playas y la oferta cultural del cantón, lo que implica, desarrollar nuevos segmentos del mercado.

\section{Situación actual}

En el Ecuador existe un total de 397.233 personas con discapacidad ${ }^{2}$, las cuales tienen todo su derecho a que se les tenga en cuenta en las estrategias de desarrollo e inclusión social. En el cantón Playas no existe la accesibilidad adecuada para ellas. Por tanto, hay que crear infraestructuras que incluyan estacionamientos especiales, rampas, señaléticas, pasarelas de superficie plana, baños especiales y servicios asociados, como sillas anfibias (que pueden ser introducidas al agua y maniobradas por un tercero)

\subsection{Proyecto "Señalización Vial, Urbana, Ruraly de sitios de Patrimonio Cultural"}

La infraestructura y equipamiento turístico es primordial para permitir la llegada de

2. Datos del Registro Nacional de Discapacidades (septiembre 2014). Para una información más detallada consultar: Consejo Nacional de Igualdad de Discapacidades. Estadísticas-Personas con discapacidad. http:// www.consejodiscapacidades.gob.ec/ 
visitantes y/o turistas a la localidad. En este sentido, se debe implementar un plan de señalización en las áreas rurales, comunitarias y en los sitios de patrimonio cultural. Una señalización turística adecuada es un elemento prioritario en la ordenación del sistema turístico. El objetivo de este proyecto es satisfacer las exigencias de señalización que requieren los visitantes y turistas que llegan al cantón Playas.

\section{Situación actual}

Dentro del cantón Playas la señalización turística es casi nula. En este sentido, se desconoce en muchas ocasiones la ruta para ir a otras comunidades. Por otra parte, no existen señales que indiquen las ubicaciones de establecimientos principales, tales como centro de información turística, sitios patrimoniales, hoteles, restaurantes, centro comercial, entre otros. Esta deficiencia es un obstáculo para la puesta en valor e incorporación del consumo de los recursos que integran el patrimonio turístico de la localidad. Con la implementación de señales turísticas se espera que el visitante pueda encontrar con facilidad los lugares que desee visitar. Lo anterior identifica al turista con su destino.

Dentro de las señalizaciones necesarias se citan: señalización promocional en carretera, señalización direccional de las oficinas de información turística, señalización "in situ" de los elementos patrimoniales puestos en valor y señalización de planta turística principal del cantón Playas (hoteles, restaurantes, bares, agencias de viajes).

\section{Monitoreo, seguimiento y evaluación}

La implementación de la propuesta del Modelo de Sostenibilidad Sociocultural de Desarrollo del Turismo para el cantón Playas es un reto para todos los actores locales del territorio donde la calidad de vida, la equidad y la integración

Indicadores de Monitoreo, seguimiento y evaluación de los programas y proyectos

\begin{tabular}{|c|c|c|}
\hline Programas & Proyectos & Indicadores \\
\hline $\begin{array}{l}\text { 1. Recuperación, revalorización } \\
\text { y desarrollo del patrimonio } \\
\text { cultural, histórico e intangible con } \\
\text { perspectivas de sostenibilidad. }\end{array}$ & $\begin{array}{l}\text { 1.1 Restauración y recuperación del edificio } \\
\text { de la ex Academia Militar Juan Gómez } \\
\text { Rendón. } \\
\text { 1.2 Revalorización de las balsas de tres } \\
\text { boyas. } \\
\text { 1.3 Reestructuración del diseño de las } \\
\text { embarcaciones de los pescadores de } \\
\text { Puerto Engabao. } \\
\text { 1.4 Creación de una ruta turística que realce } \\
\text { la identidad y cultura del cantón Playas. }\end{array}$ & $\begin{array}{l}\text { - Número de sitios históricos-culturales } \\
\text { patrimoniales recuperados. } \\
\text { - Números de balsas y embarcaciones } \\
\text { recuperadas y puestas en valor. } \\
\text { - Número de sitios patrimoniales con adecuada } \\
\text { interpretación. } \\
\text { - Número de rutas turísticas puestas en valor. } \\
\text { - Número de establecimientos turísticos que se } \\
\text { identifican con los componentes de la cultura } \\
\text { local (mobiliario, vestimenta, comida, etc.). }\end{array}$ \\
\hline $\begin{array}{l}\text { 2. Centro de Espectáculos y } \\
\text { Expresiones Culturales. }\end{array}$ & 2.1 Creación de una concha acústica. & $\begin{array}{l}\text { - Número de espectáculos culturales que se } \\
\text { realizan en el cantón Playas por año. }\end{array}$ \\
\hline 3. Infraestructura Turística & $\begin{array}{l}\text { 3.1 Creación de un mirador turístico en } \\
\text { Puerto Engabao. }\end{array}$ & $\begin{array}{l}\text { - Cantidad de visitantes y turistas que disfrutan } \\
\text { del mirador. }\end{array}$ \\
\hline 4. Facilitación Turística & $\begin{array}{l}\text { 4.1 Centro de asistencia al turista. } \\
\text { 4.2 Accesibilidad a las playas y sitios } \\
\text { patrimoniales para discapacitados. } \\
\text { 4.3 Señalización vial, urbana, rural y de } \\
\text { sitios de patrimonio cultural del Cantón } \\
\text { Playas. }\end{array}$ & $\begin{array}{l}\text { - Número de visitantes y turistas que visitan el } \\
\text { centro de asistencia y queden satisfechos con } \\
\text { sus servicios. } \\
\text { - Número de personas con discapacidad que } \\
\text { visitan el cantón Playas y queden satisfechos } \\
\text { con la accesibilidad a los lugares visitados. } \\
\text { - Número de señaléticas instaladas en sitios } \\
\text { estratégicos. }\end{array}$ \\
\hline
\end{tabular}

Fuente: Elaboración propia. 
social deben ser el eje conductor de todas las estrategias, programas y proyectos propuestos. En este sentido, los indicadores que se proponen son un marco de referencia.

El monitoreo, seguimiento y evaluación de las propuestas se enmarcarán en un proceso de cooperación y negociación entre actores- En este se deben unir fuerzas y recursos que permitan formas de colaboración para estimular las iniciativas locales y concretarlas.

\section{Conclusiones}

La investigación realizada confirma la hipótesis de investigación. Es decir, el cantón Playas tiene recursos socioculturales que constituyen la base de sus capacidades actuales y/o potenciales para el desarrollo del turismo; entonces, es viable diseñar la propuesta de un modelo de sostenibilidad sociocultural a partir de las interrelaciones que se establecen entre los turistas y la población local.

Un problema importante identificado ha sido la descoordinación y falta de comunicación entre los actores presentes en el territorio. Dicha descoordinación es provocada por intereses individuales de los diferentes grupos de poder que se encuentran en el cantón Playas. Por tanto, es vital que se lleve a cabo un proceso de cooperación entre los actores locales para el logro de estrategias de desarrollo, proyectos y programas.

La investigación confirmó que el 99\% (Quintero Santos, 2014b:37) de la demanda turística que visita al cantón lo hace para disfrutar de sus extensas playas. En este sentido, la estacionalidad de la demanda es muy marcada: alta y baja. La primera se concentra en los meses de marzo-abril que se define como temporada alta de la costa y julio-agosto que se define como temporada alta de la sierra. Por lo tanto, se hace necesario diversificar la oferta para darle valor el patrimonio cultural del cantón.

El cantón Playas además de sus atractivos naturales, como las playas, posee otros atractivos, tales como manifestaciones culturales, bienes arqueológicos, bienes inmateriales e inmuebles que todavía no son explotados turísticamente para su disfrute. En este sentido, se han identificado propuestas para revalorizar la identidad patrimonial y cultural del territorio. Sin embargo, aún no ha existido la intervención de los organismos competentes ni del sector privado para realizar las inversiones necesarias que permitan ejecutarlas.

La investigación permitió constatar la falta de comunicación y coordinación entre dependencias y entidades gubernamentales, el sector privado y la población civil. Esta desventaja no permite el desarrollo de una política turística sostenible que integre los intereses de los actores locales.

En este sentido, el modelo de sostenibilidad sociocultural propuesto es una vía para unir esfuerzos que potencien la recuperación, revalorización y desarrollo del patrimonio cultural e histórico del cantón Playas. Este contribuirá a diversificar la oferta turística y a poner en valor el patrimonio sociocultural del territorio.

\section{Agradecimiento}

Agradezco a la Secretaría Nacional de Educación Superior, Ciencia y Tecnología (SENESCYT) del Ecuador que a través del proyecto PROMETEO "Viejos Sabios", ha hecho posible mi estancia de investigación en Ecuador y la realización de artículos científicos.

\section{Referencias bibliográficas}

Alburquerque, F. (2004). Desarrollo económico local y descentralización en América Latina. En: Revista CEPAL Vol. (82), pp.157-171.

Berger, E. (2000). "Economics of Tourism" Institute of Tourism and Hotel Management, Klessheim, Salzburg, Austria, pp.16-17.

Dachary A., y Burne A., (2002). Globalización, turismo y sustentabilidad. México: Universidad de Guadalajara.

CET (Comisión Europea de Turismo) y OMT (Organización Mundial del Turismo) (2013). Manual de desarrollo de productos. Madrid: OMT.

Crosby, A. y Moreda, A. (1999). Desarrollo y gestión del turismo en áreas rurales y naturales. Madrid: Centro Europeo de Formación Ambiental y Turística. 
Díaz Álvarez, A. (1996). Turismo y Medio Ambiente: análisis económico. En: A. Pedreño Muñoz (director). Introducción a la economía del turismo en España. (pp. 275-293), Madrid: Editorial Civitas, S.A.

GADMCP (Gobierno Autónomo Descentralizado Municipal Cantón Playas) (2006) Evaluación Ambiental Estratégica del Turismo Costero: Cantón Playas. Provincia del Guayas, Guayaquil.

(2009a). Plan de Desarrollo y Ordenamiento Territorial 2009-2014. Provincia del Guayas, Guayaquil.

(2099b). Hacia un nuevo Modelo de Desarrollo para Playas. Plan Estratégico de la Ilustre Municipalidad del Cantón playas 2009 2014. Provincia del Guayas, Guayaquil.

(2012). Prioridades para el desarrollo integral Cantón Playas. Articulación de Redes Territoriales (ART). Provincia del Guayas, Guayaquil.

GPG (Gobierno Provincial del Guayas) (2012a) "Plan de Desarrollo y Ordenamiento Territorial de la Provincia del Guayas 2012-2021”. Provincia del Guayas, Guayaquil

(2012b). Guía Turística del Guayas. Provincia del Guayas, Guayaquil.

(2012c). Plan de Desarrollo y Ordenamiento Territorial de la Provincia del Guayas 2012-2021 Versión 003. Provincia del Guayas, Guayaquil.

INPC (Instituto Nacional de Patrimonio Cultural) (2010). Decreto de emergencia del patrimonio cultural: Un aporte inédito al rescate de nuestra identidad. Primera Fase, Quito.

(2011). Guía de bienes culturales del Ecuador. Quito

Ministerio de Turismo del Ecuador (2009). Actualización del Plan Estratégico de Desarrollo Turístico del Cantón Playas 2009 - 2014. Provincia del Guayas, Guayaquil.

(2007) Plan Estratégico de Desarrollo de Turismo Sostenible para Ecuador PLANDETUR 2020. Quito, Ecuador.

Ministerio del Ambiente (2010). Lineamientos para la creación de áreas protegidas municipales y directrices para su incorporación al subsistema de gobiernos autónomos descentralizados del sistema nacional de áreas protegidas. Editorial Ministerio del Ambiente del Ecuador. Quito.

Pedreño Muñoz, A. (1996). Introducción a la Economía del Turismo en España. Madrid: Editorial Civitas S.A.

Picornell, Climent, (1993). Los Impactos del Turismo. Papers de Turisme No.11. Instituto de Turismo de Valencia. Valencia. p. 83-90.

Quintero Santos, J. L. (2004). Los impactos del turismo en el desarrollo de las actividades turísticas. En: Revista Anales del Museo de América. Vol. (12), pp. 263 -274.ARAL

(2008). Turismo y desarrollo local en México. El caso del municipio de Cabo Corrientes, Estado de Jalisco. Publicación Conjunta Universidad de Guadalajara, México - Universidad Complutense de Madrid, España. Servicio de Publicaciones Centro Universitario de la Costa, Puerto Vallarta. Estado de Jalisco. México. Primera Edición.

(2013). Retos del desarrollo turístico en el cambio de la matriz productiva en Ecuador. En: Revista FOCUS Edición 59. Vol. (8). Edición No. 59, pp.34-35.

(2014a). Reflexiones acerca de la investigación científica en turismo. Revista RES NON VERBA. Revista Ciencia, Innovación y Sociedad del Conocimiento. Vol. (5). Edición Abril 2014. ISSN 1390-6968, pp. 28-42.

(2014b). Sectores Económicos del Cantón Playas: sus vínculos con el turismo. Revista Anais Brasileiros de Estudios Turísticos (ABET), JUIZ DE FORA, Vol.4 (2), pp. $32-42$.

Rivas, J. I. (2010). Turismo sostenible o insostenible, esa es la cuestión: indicadores proxy para una planificación turística ambientalmente responsable. En: Revista Clm. economía. Vol. (1 5), pp. 375 - 4 1 8. Castilla-La Mancha.

Samaniego Rivera, J. (2012). Plan de Manejo del Área Nacional de Recreación Playas de Villamil Producto 1: Diagnóstico Integral. Provincia del Guayas, Guayaquil.

Secretaría Nacional de Planificación y Desarrollo (2013). Plan Nacional para el Buen Vivir 2003-2017. Quito. 
